\title{
Angelman Syndrome in a Filipino Child
}

\author{
Roan Eireen L. Buenaventura, MD, ${ }^{1}$ Ebner Bon G. Maceda, MD ${ }^{1,2}$ and Leniza De Castro-Hamoy, MD ${ }^{1,2}$ \\ ${ }^{1}$ Department of Pediatrics, Philippine General Hospital, University of the Philippines Manila \\ ${ }^{2}$ Institute of Human Genetics, National Institutes of Health, University of the Philippines Manila
}

\begin{abstract}
Angelman syndrome (AS) is a distinct condition that presents with severe developmental delay. This condition also presents with speech impairment, ataxia/tremor, and inappropriate laughter. Some other features in most patients include microcephaly, seizures, tongue protrusion, wide mouth, and hypopigmentation.

This case aims to emphasize the value of diagnosis in a patient with developmental delay. The diagnosis allows anticipation of the development of other possible problems and guides appropriate management. This report also aims to increase awareness regarding the condition.

Here we present a 71-month-old Filipino male with developmental delay at six months, seizures at 10 months with a note of an overall happy demeanor and frequent inappropriate bouts of laughter at one year old. The patient also presented with severe stunting, microcephaly, wide mouth and ataxic gait. Through pattern recognition and the updated consensus of its diagnostic criteria, and confirmation via fluorescence in situ hybridization (FISH), which revealed a deletion in chromosome 15q11, the diagnosis of AS was made.
\end{abstract}

This case re-emphasizes the role of clinical recognition of this condition and its confirmation via cytogenetic techniques like FISH, which will aid appropriate management and counseling for the patient and their families.

Key Words: Angelman syndrome, 15q11 deletion, developmental delay

\section{INTRODUCTION}

Angelman syndrome (AS) is a genetic condition caused by a deficiency in ubiquitin protein ligase E3A $(U B E 3 A)$ gene expression due to various abnormalities in chromosome $15 .{ }^{1}$ It was first described in 1965 by the English pediatrician, Dr. Harry Angelman, who described three children with severe learning disability, speech delay, ataxia, jerky movement, inappropriate laughter, epilepsy, and subtle dysmorphic facial features. It was initially named "happy puppet" syndrome based on a painting by Giovanni Francesco Carota in Verona, but eventually changed to its current name due to its being pejorative.

Worldwide, it has an estimated prevalence of 1 in 12,000 to 24,000 , classifying it as a rare condition. ${ }^{2}$ Prevalence studies in Asia for this case are very limited. In the Philippines, there's a reported case of AS but no prevalence studies yet. The registry of the Section of Clinical Genetics, Department of the Pediatrics of the Philippine General Hospital lists three patients confirmed by FISH and 10 clinically diagnosed cases of AS. It is a condition requiring lifelong supervision and multidisciplinary management, presenting with severe developmental delay and epilepsy. Hence, this report aims to increase awareness, which may result in early diagnosis and better care for AS patients.

Corresponding author: Roan Eireen L. Buenaventura, MD Department of Pediatrics Philippine General Hospital University of the Philippines Manila Taft Avenue, Manila 1000, Philippines Email:roaneireen@gmail.com 


\section{CASE}

The patient is a 71-month-old male who presented with developmental delay. He was born full-term to a 24-yearold primigravid via spontaneous vaginal delivery. He was apparently well until at six months of age and then the mother noted delays in both motor and language domains. No consults were done until 10 months of age, when he presented with generalized epilepsy and was maintained on phenobarbital. Eventually, valproic acid was added due to poor control. He presented with sleep disturbance at 24 months of age. He was the eldest child of a sibship of three born to a healthy non-consanguineous couple of Filipino descent (Figure 1).

The developmental profile was evaluated based on the interview with his mother, clinical observations and examination. The Battelle Developmental Inventory (Second Edition) was likewise administered, showing delays in all domains of development. Developmental quotient (DQ) for the different domains are as follows: personal-social -17 , adaptive -19 , gross motor -22 , fine motor -18 , receptive language -13 , expressive language -6 , and cognitive- 21 .

On physical examination, he had severe stunting (95 $\mathrm{cm})$ and microcephaly $(47.2 \mathrm{~cm})$. He had a generally happy demeanor, with tongue thrusting, drooling and frequent inappropriate laughter. He had brachycephaly, deep-set eyes, wide mouth, widely spaced teeth, hypopigmented skin and an ataxic gait (Figure 2).

Workup showed a mild global paucity of cerebral white matter with no additional intracranial abnormality on cranial magnetic resonance imaging with gadolinium. EEG revealed generalized polysharps against a slow background rhythm. The auditory evoked response test showed intact auditory pathways. A deletion in region 11 in the long arm of chromosome 15 was seen on FISH. Results of the enumerated tests taken together are consistent with AS.

The patient is maintained on phenobarbital $(3 \mathrm{mg} / \mathrm{kg} /$ day) and valproic acid ( $40 \mathrm{mg} / \mathrm{kg} /$ day). He is on speech therapy for language stimulation and functional communication, occupational therapy for the development of fine motor and adaptive skills and to allow participation in play and

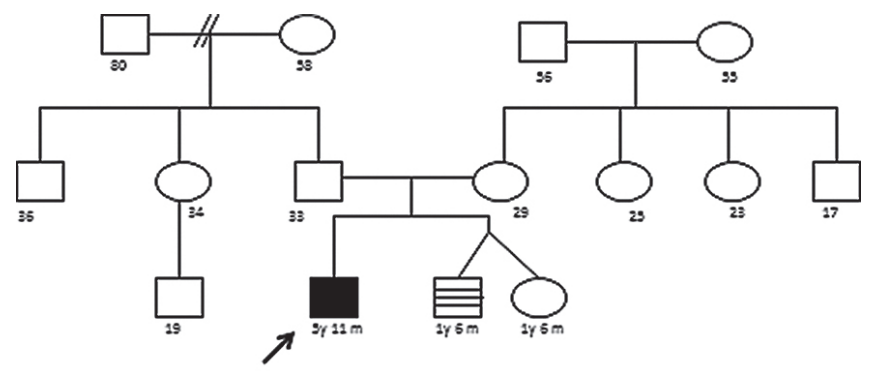

Lumoscacral

Figure 1. Three-generation pedigree of the patient. physical therapy for balance and coordination. Mother was advised on sleep hygiene to address sleep disturbance.

The patient has been consulting regularly for the past two years at the Philippine General Hospital Outpatient Department under the services of General Pediatrics, Genetics, and Developmental Pediatrics. He is undergoing speech, physical and occupational therapy. He is maintained on valproic acid and phenobarbital with good seizure control. $\mathrm{He}$ is able to maintain eye contact but with a note of short attention span, no word utterance, able to follow simple commands and needs assistance with activities of daily living.

\section{DISCUSSION}

Angelman syndrome is a genetic condition caused by a deficiency in the $U B E 3 A$ gene expression due to various abnormalities in chromosome $15 .^{1}$ The defect is in the maternally inherited gene, wherein deficient function can be caused by a deletion, uniparental disomy, imprinting defect or an inherently pathogenic gene. Under normal conditions, $U B E 3 A$ gene produces ubiquitin protein ligase $\mathrm{E} 3 \mathrm{~A}$ that is involved in tagging substances for protein degradation via the ubiquitin proteasome pathway. This protein has a critical role in synaptic plasticity. ${ }^{3}$ Hence, the majority of the features of AS are neurodevelopmental.

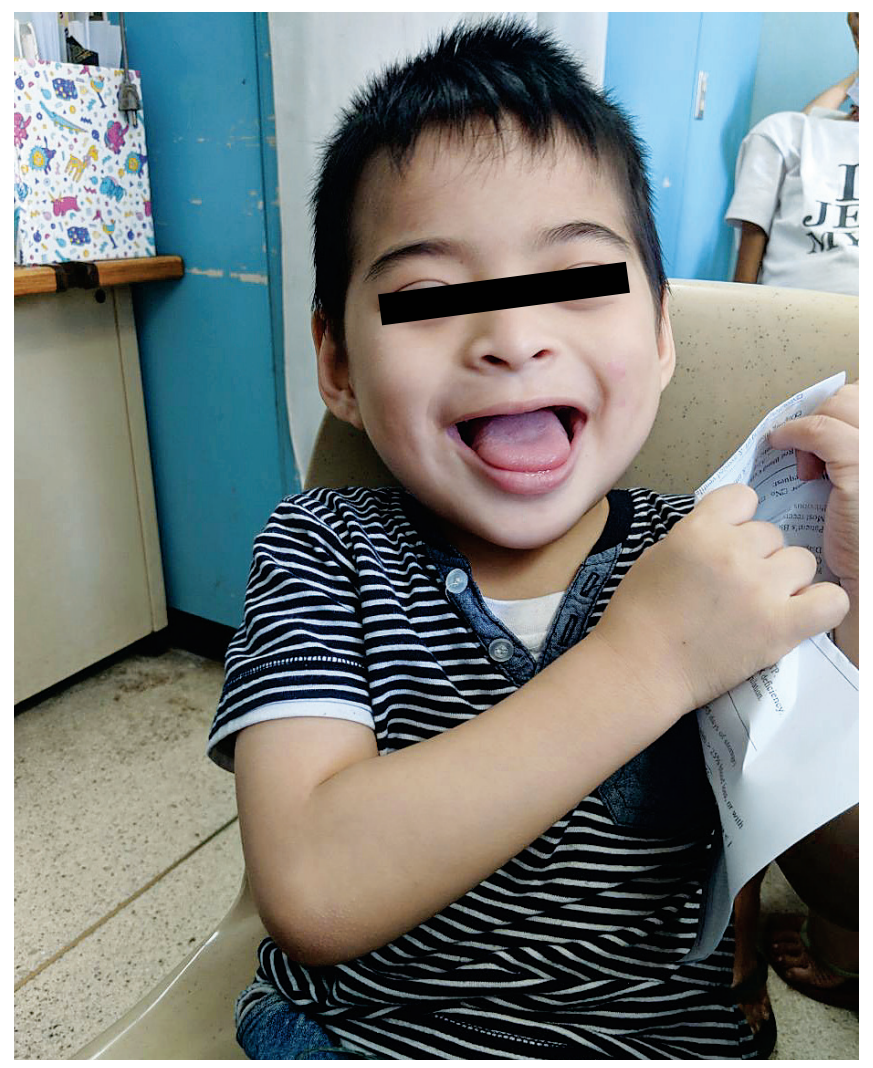

Figure 2. Photo of the patient showing a generally happy demeanor, microcephaly, deep set eyes, and a wide mouth. 
The clinical manifestations of the condition span all organ systems. Clinical features that are consistently seen are severe developmental delay, movement disorder such as ataxia or tremors, behavioral uniqueness described as a happy demeanor with bouts of inappropriate laughter and speech impairment. Seizures and impaired head growth with microcephaly are also frequently present. Less common features include protruding tongue with tongue thrusting, drooling, feeding difficulties, wide mouth with widely spaced teeth, hypopigmentation, wide-based gait, abnormal sleep pattern, obesity, scoliosis and fascination with water. ${ }^{4}$ In our patient, most of these features were noted (Table 1). It is noted that both consistent (present in $100 \%$ of cases) and frequent (present in $>80 \%$ of cases) features are present in our patient.

FISH is used to confirm the presence or absence of chromosome $15 \mathrm{q} 11$ deletions in $\mathrm{AS}$, which is the most common etiology of this condition, seen in 75 to $80 \%$ of cases. $^{5}$ Non-deletion cases of AS would therefore not be detected by this method and would require other techniques like methylation studies. ${ }^{6}$ In our patient, the deletion was noted on FISH.

In the Philippines, there is only one previously reported case of a cytogenetically confirmed case of AS. It was in a four and a half-year-old boy who manifested with feeding problems at two months old, developmental delays at four months old, frequent smiling at nine months old, seizures at two and $1 / 2$ years old, and sleep disturbance at four years old. ${ }^{7}$ Manifestations are similar to the case being presented, although onset of seizures is later and the patient in the study had feeding difficulties which were not present in the patient of this report.

The importance of the diagnosis of AS lies in the management of the patient. The cornerstone of treatment is supportive and involves treatment of manifestations, prevention of secondary complications and surveillance. ${ }^{8}$ Manifestations include seizure, behavioral problems, movement disorders, gross developmental delay and sleep disturbance. Studies on antiepileptic drugs (AEDs) used in AS have cited valproic acid, benzodiazepenes such as nitrazepam and clonazepam, and phenobarbital as the most commonly used drugs. ${ }^{9}$ The use of carbamazepine and gabapentin has been advised against because of a paradoxical increase in seizure episodes. ${ }^{10}$ The choice of AEDs in AS shows the importance of its diagnostic confirmation. In addition, physical, speech and occupational therapy are essential, with emphasis on the development of non-verbal communication and the development of self-help skills. As with other known conditions, surveillance is done for possible complications such as anti-epileptic drug overdose, especially since movement disorder manifestation can be mistaken for a seizure. ${ }^{8}$ In addition, regular monitoring of growth and screening for scoliosis is done, as children with AS have been shown to be prone to developing scoliosis and excessive appetite as they get older. ${ }^{4}$ The patient is maintained on valproic acid and phenobarbital. He is undergoing regular speech, occupational and physical therapy. Surveillance is being done at the Philippine General Hospital Outpatient Department under the pediatric service.

Table 1. Comparison of Clinical Features of our patient with the previously reported cases of Angelman syndrome

\begin{tabular}{|c|c|}
\hline $\begin{array}{l}\text { Clinical Features of Angelman syndrome } \\
(\text { Williams et al, 2005) }\end{array}$ & $\begin{array}{l}\text { Features present } \\
\text { in our patient }\end{array}$ \\
\hline $\begin{array}{l}\text { A. Consistent (100\%) } \\
\text { Severe developmental delay } \\
\text { Movement or balance disorder (usually ataxia of gait) } \\
\text { Behavioral uniqueness (happy demeanor with bouts of inappropriate laughter) } \\
\text { Speech impairment }\end{array}$ & $\begin{array}{l}(+) \\
(+) \\
(+) \\
(+)\end{array}$ \\
\hline $\begin{array}{l}\text { B. Frequent (> 80\%) } \\
\text { Delayed, disproportionate growth in head circumference (usually resulting in microcephaly) } \\
\text { Seizure, onset usually }<3 \text { years of age } \\
\text { Abnormal EEG }\end{array}$ & $\begin{array}{l}(+) \\
(+) \\
(+)\end{array}$ \\
\hline $\begin{array}{l}\text { C. Associated (20-80\%) } \\
\text { Flat occiput } \\
\text { Occipital groove } \\
\text { Protruding tongue } \\
\text { Tongue thrusting } \\
\text { Feeding problems } \\
\text { Prognathia } \\
\text { Wide mouth, wide-spaced teeth } \\
\text { Frequent drooling } \\
\text { Excessive chewing/mouthing behaviors } \\
\text { Strabismus } \\
\text { Hypopigmented skin } \\
\text { Hyperactive lower extremity deep tendon reflexes } \\
\text { Uplifted, flexed arm position especially during ambulation } \\
\text { Wide-based gait } \\
\text { Increased sensitivity to heat }\end{array}$ & $\begin{array}{l}(+) \\
(+) \\
(+) \\
(+) \\
- \\
- \\
(+) \\
(+) \\
- \\
- \\
(+) \\
(+) \\
(+) \\
-\end{array}$ \\
\hline
\end{tabular}


The life expectancy of AS is not yet established. Published papers report mixed findings. There are reports suggesting reduced life expectancy by 10 to 15 years. However, there also reports of individuals with AS beyond 70 years old. ${ }^{11}$ Medical issues that were identified in adult patients with AS include seizures, sleep disturbance, aspiration risk, gastrointestinal problems, orthopedic concerns, obesity, mobility, vision, self-injurious behavior, and anxiety. ${ }^{12}$

With the advances in research, therapeutic options to improve the care of patients are being investigated. One proposed therapeutic intervention for AS is reversing the silencing of the paternal UBE3A gene on the basis of the maternal gene being the defective component and the assumption that the paternal gene is unaffected. ${ }^{13}$ Introduction of a viral vector that would express a functional UBE3A gene has also been proposed as a form of gene therapy ${ }^{14}$ However, studies on the proposed interventions are still lacking and the results of existing studies remain to be inconclusive. The latest studies on animal models show great potential. However, there are still no human studies on the proposed interventions. ${ }^{15}$

\section{CONCLUSION}

In conditions like AS, pattern recognition is important in clinching the diagnosis. A multidisciplinary effort is necessary for caring for individuals with AS to ensure holistic management. Lifelong care and support are needed for individuals with AS. Highlighting the need to increase awareness regarding the condition is of value so that efforts can be made to further improve its management and to provide support to families taking care of them.

\section{Consent}

Written informed consent was obtained from the mother of the patient for publication of this case report and the accompanying image.

\section{Acknowledgments}

We would like to extend our sincerest gratitute to Dr. Charlotte Averill Tan and Dr. Ana Katherina Rodriguez-Go of the Section of Developmental \& Behavioral Pediatrics, as well as the Clinical Genetics Unit of the the Institute of Human Genetics, for their assistance in providing necessary data for this report.

\section{Statement of Authorship}

All authors participated in data collection and analysis, and approved the final version submitted.

\section{Author Disclosure}

All authors declared no conflicts of interest.

\section{Funding Source}

None.

\section{REFERENCES}

1. Dan B. Angelman syndrome: Current understanding and research prospects Epilepsia. 2009 Nov; 50(11):2331-9. doi: 10.1111/j.15281167.2009.02311.x.

2. Clayton-Smith J, Laan L. Angelman syndrome: a review of the clinical and genetic aspects. J Med Genet. 2003 Feb;40(2):87-95. doi: 10.1136/jmg.40.2.87

3. Dindot SV, Antalffy BA, Bhattacharjee MB, Beaudet AL. The Angelman syndrome ubiquitin kigase localizes to the synapse and nucleus, and maternal deficiency results in abnormal dendritic spine morphology. Hum Mol Genet. 2008 Jan; 17(1):111-8. doi: 10.1093/ $\mathrm{hmg} / \mathrm{ddm} 288$.

4. Angelman Syndrome Guideline Development Group, Management of Angelman Syndrome: A Clinical Guideline [Internet]. 2011 [cited 2019 Apr]. Available from: https://www.orpha.net/data/patho/Pro/ en/AngelmanGuidelines2011.pdf

5. Valente KD, Andrade JQ Grossman RM, Kok F, Fridman C, KOiffmann CP, et al. Angelman Syndrome: Difficulties in EEG pattern recognition and possible misinterpretations. Epilepsia. 2003 Aug; 44(8):1051-63. doi: 10.1046/j.1528-1157.2003.66502.x.

6. Bettio D, Rizzi N, Giardino D, Grugni G, Briscioli V, Selicorni A, et al. FISH analysis in Prader-Willi and Angelman Syndrome patients. Am J Med Genet. 1995 Mar; 56(2):224-8. doi: 10.1002/ajmg.1320560222.

7. Cutiongco EM, Perez SG, Ortiz MH. Angelman Syndrome: A case report [abstract]. The Philippine Journal of Neurology. 2003 Jul.

8. Dagli AI, Mueller J, Williams CA. Angelman Syndrome [Internet]. National Center for Biotechnology Information. U.S. National Library of Medicine; 2017 [cited 2019 Apr6]. Available from: https://www.ncbi.nlm.nih.gov/books/NBK1144/?report=printablel

9. Shaaya EA, Grocott OR, Laing O, Thibert RL. Seizure treatment in Angelman syndrome: A case series from the Angelman Syndrome Clinic at Massachusetts General Hospital. Epilepsy Behav. 2016 Jul;60:138-41. doi: 10.1016/j.yebeh.2016.04.030.

10. Pelc K, Boyd SG, Cheron G, Dan B. Epilepsy in Angelman syndrome. Seizure. 2008 Apr; 17(3):211-7. doi: 10.1016/j.seizure.2007.08.004.

11. Prasad A, Grocott O, Parkin K, Larson A, Thibert RL. Angelman syndrome in adolescence and adulthood: A retrospective chart review of 53 cases. Am J Med Genet. 2018 Jun; 176(6):1327-34. doi: 10.1002/ajmg.a.38694.

12. Larson AM, Shinnick JE, Shaaya EA, Thiele EA, Thibert RL. Angelman Syndrome in adulthood. Am J Med Genet A. 2015 Feb; 167A(2):331-44. doi: 10.1002/ajmg.a.36864.

13. Meng L, Ward AJ, Chun S, Bennett CF, Beaudet AL, Rigo F. Towards a therapy for Angelman syndrome by targeting a long non-coding RNA. Nature. 2015 Feb; 518(7539):409-12. doi: 10.1038/nature13975.

14. Tan W-H, Bird LM. Angelman syndrome: Current and emerging therapies in 2016. Am J Med Genet Part C Semin Med Genet. 2016 Dec; 172(4):384-401. doi: 10.1002/ajmg.c.31536.

15. Daily JL, Nash K, Jinwal U, Golde T, Rogers J, Peters MM, et al. Adeno-Associated Virus-Mediated Rescue of the Cognitive Defects in a Mouse Model for Angelman Syndrome. PLoS One. 2011; 6(12):e27221. doi: 10.1371/journal.pone.0027221.

16. Williams CA, Beaudet AL, Clayton-Smith J, Knoll JH, Kyllerman M, Laan LA, et al. Angelman Syndrome 2005: Updated consensus for diagnostic criteria. Am J Med Genet A. 2006 Mar; 140(5):413-8. doi: 10.1002/ajmg.a.31074. 